NBER WORKING PAPER SERIES

APPLIED WELFARE ECONOMICS WITH

DISCRETE CHOICE MODELS

Harvey S. Rosen

Kenneth A. Small

Working Paper No. 319

NATIONAI BUREAU OF ECONOMIC RESEARCH

1050 Massachusetts Avenue

Cambridge MA 02138

February 1979

The research reported here is part of the NBER's research program in Business Taxation and Finance and was supported in part by the National Science Foundation, grant no. s0c77-07082. The views expressed are those of the authors. We have received useful comments from David Bradford, Peter Diamond, Daniel Feeburg, Arnold Harberger, Richard Quandt and Robert Willig. 
NBER Working Paper 319

February 1979

\title{
Applied Welfare Economics with Discrete Choice Models
}

\author{
SUMMARY
}

Economists have been paying increasing attention to the study of situations in which consumers face a discrete rather than a continous set of choices. Such models are potentially very important in evaluating the impact of government programs upon consumer welfare. But very little has been said in general regarding the tools of applied welfare economics in discrete choice situations.

This paper shows how the conventional methods of applied welfare economics can be modified to handle such cases. It focuses on the computation of the excess burden of taxation, and the evaluation of quajity change. The results are applied to stochastic utility models, inciuding the popular cases of prolsit and logit aralysis. Throughout, the emphasis is on providing rigorous guidelines for carrying out applied work.

Harvey S. Rosen Kenneth A. Small Department of Economics Princeton University Princeton, N.J. 08540

(609) $452-4022$ 
I. Introduction

Economists are paying increasing attention to the study of situations in which consumers face a discrete rather than a continuous set of choices. A considerable literature has grown covering econometric methodology and applications to a wide variety of situations. ' In a few specific cases, estimates of discrete choice models have been employed for welfare analysis. 2 Travel demand researchers have developed "composite cost" and "accessibility" measures to evaluate the desirability of various states (Williams [1977], Ben-Akiva and Lerman [1978]), but the relationship of these to conventional welfare criteria has not been thoroughly explored. Indeed, very little has been said in general regarding the validity of the tools of applied welfare economics in discrete choice situations.

Nevertheless, in at least two areas in which discrete choice models are applied, welfare judgments are of paramount interest. The first is the analysis of taxes and subsidies. Econometric studies of the impacts of taxes on labor supply, savings, and housing decisions have permitted calculation of the welfare cost or "excess burden" of the tax feature under consideration. 3 Traditionaliy, such studies have assumed that the taxed activity will be pursued regardless of the existence of the tax.

However, instances in which taxes influence discrete choices are numerous and important. For example, it has been suggested that the federal tax treatment of owner-occupied housing not only increases the quantity demanded of owneroccupied housing services, but also influences whether or not an individual owns a home at all [Rosen, forthcoming]. For secondary earners, taxes affect not only the number of hours of work, but also whether or not participation in the labor

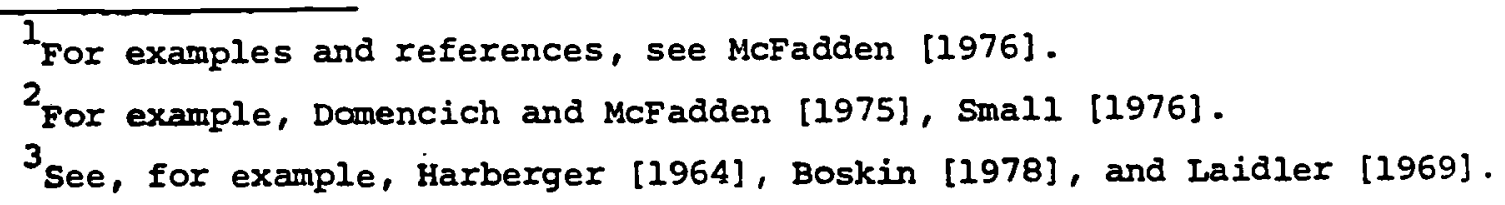


market takes place [Heckman, 1974]. Even for primary workers, taxes may influence not only the hours spent at a given occupation, but the choice between occupations as well.

A second important area is the analysis of quality changes in goods and services. Numerous studies in such areas as transportation, education, health care, child care, and pollution contain explicit or implicit welfare evaluations of public policies which change the quality of some publicly or privately supplied good. In many cases, the good affected is subject to discrete choice: mode of transportation, public or private schools, type of health care, type of child care, and location of recreational activities all serve as examples.

The purpose of the present paper is to demonstrate that the conventional methods of applied welfare economics can be generalized to handle cases in which discrete choices are involved. We think it important for several reasons to set out the generalization carefully. First, there has been some suggestion that conventional welfare change computations may have no relevance in discrete choice cases. 4 second, as the econometric estimation of discrete choice models of many types gains in popularity, it is useful to have a clear statement regarding their use in applied welfare economics. Finally, the presence of discrete choice introduces some differences in the relation between ordinary and compensated demand curves which alters the way in which empirical approximations should be carried out.

In section II we review the computation of the Hicksian compensated variation for the "standard" case in which there are price-induced changes in quantity demanded by each individual. We also note its relation to the

\footnotetext{
4 For example, Ben-Porath and Bruno [1977] state that in Israel, the pre-1975 tax structure was ... "less a deterrent to work as such than an inducement to search for untaxable types of work" (our emphasis). They suggest that "The concept of excess burden is not particularly well defined in this case ..." (p. 289).
} 
Harberger "excess burden" and to the Marshallian consumer's surplus. In section III it is shown how the computations are performed for circumstances in which discrete choice is involved, and section IV extends the result to quality changes. Section $\mathrm{V}$ discusses in detail the application of the results to stochastic utility models, including the cases of probit and logit analysis. Throughout, the emphasis is on providing rigorous guidelines for carrying out applied work.

\section{Continuous Choice}

In this section we review the justification for measuring price-induced utility changes as areas to the left of the appropriate compensated demand curves. The basic analytical tool is the expenditure function, which is treated conciselý and elegantly in Diamond and MCFadden [1974].

Suppose that a consumer has a twice differentiable, strictly quasiconcave utility function $u$ defined over the commodities $x_{n}$ and $x_{1}$, where $x_{n}$ is taken to be the numeraire. The two good case is chosen for convenience; the results generalize easily to an arbitrary number of commodities. The consumer maximizes

$$
u=u\left(x_{n}, x_{1}\right)
$$

subject to the budget and non-negativity constraints

$$
\begin{aligned}
& x_{n}+p_{1} x_{1}=y \\
& x_{j} \geq 0 \quad j=n, 1
\end{aligned}
$$

where $p_{1}$ is the price of good $l$, and $y$ is income. 
Maximization of (2.1) subject to (2.2) yields the ordinary demand functions

$$
x_{j}=x_{j}\left(P_{1}, y\right) \quad j=n, l .
$$

We assume an interior solution $\left(x_{j}>0\right)$ with respect to both goods. Substituting (2.4) into (2.1) we define the consumer's indirect utility function:

$$
v\left(p_{1}, y\right)=v\left(x_{n}\left(p_{1}, y\right), x_{1}\left(p_{1}, y\right)\right)
$$

which is known to satisfy Roy's Identity: 5

$$
-\frac{\partial v / \partial p_{1}}{\partial v / \partial y}=x_{1} .
$$

Provided that the direct utility function is strictly increasing in $x_{n}$ and is non-decreasing in $x_{1}, v$ is monotonic increasing in $y$ and can therefore be inverted to yield the expenditure function

$$
y=e\left(p_{1} u\right)
$$

The function e therefore indicates how much income is required to achieve the utility level $u$ when the price of good $l$ is $P_{l}$; it satisfies

$$
u=v\left(p_{1}, e\left(p_{1}, u\right)\right)
$$

Now suppose that the price of the first good changes from $p_{1}^{0}$ to $p_{1}^{f}$. By definition, the compensating variation associated with the price change is

$$
\Delta e=e\left(p_{1}^{f}, u^{o}\right)-e\left(p_{1}^{o}, u^{o}\right)
$$

'Roy's Identity follows from comparing the total differentials of (2.2) and (2.5) and using the first-order maximization conditions. 
This expression shows the amount of income the consumer must be given to make him as well of at price $p_{1}^{f}$ as at $p_{1}^{0}$. Mohring [1971] has forcefully argued that it is the appropriate measure for most problems of applied welfare economics. 6

The problem now is to express (2.9) in terms of the compensated demand function for $x_{1}$, which is defined by

$$
x_{1}^{c}\left(p_{1}, u\right)=x_{1}\left(p_{1}, e\left(p_{1}, u\right)\right)
$$

This is done by applying Shephard's lema:

$$
\frac{\partial e\left(p_{1}, u\right)}{\partial p_{1}}=x_{1}^{c}\left(p_{1}, u\right) \text {, }
$$

where $u$ is an arbitrarily selected utility level. ${ }^{7}$ This equation gives the compensating variation for an infinitesimal change in $p_{1} ;$ to find the compensating variation for a finite change, (2.11) is integrated:

$$
e\left(p_{1}^{f} ; u^{\circ}\right)-e\left(p_{1}^{o}, u^{o}\right)=\int_{p_{1}^{0}}^{p_{1}^{f}} x_{1}^{c}\left(p_{1}, u^{\circ}\right) d p_{1} .
$$

This gives the basic result mentioned at the start of this section; the compensating variation of a price change is the area to the left of the compensated demand curve.

This result is easily aggregated. Define the aggregate compensated deniand function for good $1, x_{1}^{c}$, as the sum of the individual compensated demand functions. $x_{1}^{c}$ depends upon prices and upon the utility levels of all consumers.

${ }^{6}$ It is employed, for example, by Hause [1975] and Diamond and McFadden [1974], both of which demonstrate that the compensating variation measure leads to the well-known Harberger formula for excess burden. Nevertheless, some controversy surrounds its use: see Chipman and Moore [1976a] and Hause [1975].

'Shephard's lemma follows from differentiating (2.8) with respect to $p_{1}$ '. and applying Roy's Identity. 
Si-ilarly, define the aggregate expenditure function, $E$, as the sum of the individual expenditure functions at these same utility levels. Then by adding the compensating variations $(2.12)$ for all consumers, we obtain:

$$
\Delta E=\int_{p_{1}^{0}}^{p_{1}^{f}} x_{1}^{c}\left(p_{1},\left\{u^{i}\right\}\right) d p_{1},
$$

where $\left\{u^{i}\right\}$ is the set of utility levels before the change.

For practical purposes, the area to the left of the compensated demand curve in (2.13) is usually calculated from an econometric estimate of the ordinary or Marshallian demand curve. ${ }^{8}$ Although the compensated demand function for an individual can, under certain conditions, be computed exactly Erom an econometric estimate of the Marshallian demand [Seade, 1978; Willig, 19763, the same is not true of aggregates. This had led to an approximation procedure, employed by a number of investigators such as Harberger [1964] and Eeldstein [1978], in which the slutsky equation is applied to the ordinary aggregate demand curve in order to obtain estimates of compensated price elasticities. This procedure is exact if (a) $\partial x_{1} / \partial y$ is the same for everyone, and (b) each individual's share of aggregate income is fixed regardless of price and income changes; in this case the slutsky equation can be aggregated. To the extent that individuals' income slopes are similar, then, this would appear to be a reasonable approsimation procedure.

For the special case in which the price change is inauced by a tax (or subsidy), (2.13) can be used to calculate the "excess burden" of the tax, i.e., the welfare loss brought about by distortions in relative prices. Following

8 It has been shown that the area under the ordinary demand curve is itself an exact measure of the utility change under very restrictive conditions in the demand function. See, for example, Chipman and Moore [1976b], Rader [1976b], or Bruce [1977]. 
Diamond and MCFadden [1974], we define excess burden as

$$
X=\Delta E-T
$$

where $T$ denotes tax receipts. The exact form which equation (2.14) takes in practice depends on the income effects generated by the uses of the tax revenues (or, alternatively, by a set of hypothetical lump-sum taxes of equal yield), and therefore depends on the distribution of these revenue uses or taxes. Although this point is well-known (see Friedman [1949], Bailey [1954], Harberger [1964], and Hause [1975]), it. is worth restating here because its implications for discrete goods, discussed in the next section, are somewhat surprising.

Let $\alpha$ and $\alpha^{c}$ be the own-price slopes of the aggregate Marshallian and compensated demand functions, respectively; and let $\omega$ be the income-slope of the former, viewed as a function of aggregate income $Y \equiv \sum y^{i}$. Then the slutsky approximation discussed above,

$$
\alpha^{c}=\alpha+x_{1} \omega
$$

can be intuitively justified from the observation that $x_{1} d p_{1}$ is the income compensation required to ameliorate the effect of a price increase ' $d p_{1}$ ' and hence $\omega \mathrm{x}_{1} d \mathrm{p}_{1}$ is the additional consumption induced if income is compensated. A linear approximation to the compensated demand curve yields

$$
\begin{aligned}
\Delta E & \simeq x_{1}^{\circ} \Delta p_{1}+\frac{1}{2} \alpha^{c}\left(\Delta p_{1}\right)^{2} \\
& =x_{1}^{\circ} \Delta_{p_{1}}+\frac{1}{2}\left[\alpha+x_{1} \omega\right]\left(\Delta p_{1}\right)^{2}
\end{aligned}
$$

where $x_{1}^{0}$ is the aggregate consumption at initial price $p_{1}^{0}$, and where $\Delta p_{1}=p_{1}^{E}-p_{1}^{\circ}$ Equation (2.17) can be viewed as the Taylor Series approximation to $\Delta E$, of second-order in $\Delta p_{1}$. 
Now consider two alternative assumptions about the uses of the tax revenues $T$ : (a) the partial equilibrium assumption that they are used in such a way as to generate no repercussions on demand for good 1 , and (b) the general equilibrium assumption that they are distributed uniformly in lump sum transfers. We again compute approximations of second order in the price change. Under assumption (a), tax revenues are computed along the Marshallian demand curve:

$$
T^{P} \simeq\left[x_{1}^{\circ}+\alpha \Delta p_{1}\right] \Delta p_{1}
$$

Under assumption $\quad(b)$, on the other hand, final demand contains an income effect $\omega^{\mathbf{G}}$, where $T^{\mathbf{G}}$ are the tax revenues, so that

$$
T^{G} \simeq\left[x_{1}^{0}+\alpha \Delta p_{1}+w T^{G}\right] \Delta p_{1}
$$

which can be solyed for $T^{G}$ and expended in a second-order Taylor series to yielō:

$$
\begin{aligned}
T^{G} & =\left[x_{1}^{0}+\left(\alpha+x_{1}(\omega) \Delta p_{1}\right] \Delta p_{1}\right. \\
& =\left[x_{1}^{\circ}+\alpha^{c} \Delta p_{1}\right] \Delta p_{1} .
\end{aligned}
$$

But this is equivalent to computing taxes along the compensated demand curve. ${ }^{9}$

Subtracting tax revenues from the compensating variation in $(2,16)$ and rearranging yields the following alternative formulae for excess burden;

(a) Partial Eq.: $\quad X^{p} \simeq \frac{1}{2}\left[\alpha^{c}-2 \alpha\right]\left(\Delta p_{1}\right)^{2}$

$$
=\frac{1}{2}\left[-\alpha+x_{2} \omega\right]\left(\Delta p_{1}\right)^{2}
$$

(b) General Eg.: $\quad \chi^{G} \simeq \frac{1}{2}\left[-\alpha^{c}\right]\left(\Delta p_{1}\right)^{2}$

$$
\left.=\frac{1}{2} I-\alpha-x_{1} \omega\right]\left(\Delta p_{1}\right)^{2}
$$

${ }^{9}$ See Hause [1975], pp. 1156-1160, for a fuller discussion of the rationale for using the compensated demand curve in computing tax revenue under general equilibrium assumptions. Note also that we are assuming a constant cost technology, i.e., introduction of the tax does not change the producer's price over the relevant region. See also Rohlfs' [1976] discussion of the adequacy of surplus welfare measures under partial equilibrium assumptions. 
The general equilibrium yersion (2.24) is the famous excess burden triangle usually associated with Harberger.

Note that, whereas the compensating variation is of first order in $\Delta p_{1}$. the excess burden is itself of second-order in $\Delta p_{1}$. Thus, the conditions given by willig [1976], wnder which the compensating variation is adequately approximated by the ordinary consumer's surplus, do not necessarily justify using the ordinary instead of the compensated demand curve for excess barden calculations. Indeed, if the general equilibrium assumptions underlying equation (2.24) prevail, then it is the best approximation (up to secondorder terms in $\Delta p_{1}$, of the excess burden, and the fractional error from using $\alpha$ instead of $\alpha^{c}$ in equation (2.24) is $\left(\alpha-\alpha^{c}\right) / \alpha^{c}=x_{1} \omega / \alpha^{c}=-\theta V \varepsilon^{c}$, where $\theta$ is the budget share of good $1, \eta$ is its income elasticity, and $\varepsilon^{c}$ is its compensated own-price elasticity. This error can be substantial for a good, such as housing, which absorbs a large portion of consumers' incomes.

For a normal good, the excess burden is positive and is smaller in the general than in the partial equilibrium context. This is because the consunption cutback caused by the price distortion is lessened by the income effects arising from the uses of the tax revenues. We will see in the next section that some of the ameleriorating income effect in the general equilibrium case is lost in discrete good models, making the potential welfare losses from taxes on such goods greater than conventional analysis would imply.

\section{Discrete Choice}

In this section, we prove the basic theorem which establishes the validity of using the area to the left of a compensated demand curve for a discrete good as a measure of the compensating variation. We take advantage of the 
notation and general plan of attack used in Section II for the continuous goods case. We then show how the use of empirical approximations for computing welfare losses is modified.

Discreteness in demand can be modelled in at least three ways. (a) Comodities may be available in continuous quantities, but in only one of a small number of mutually exclusive varieties. An example is housing. It can be purchased in either the rental or owner mode, but given the tenure choice, a continuous quantity of housing services can be consumed. (b) Goods may be available in discrete units which are so large that most consumers choose only one or two units. Examples include college degrees, transportation mode for work trips, and many consumer durables. (c) Goods may be purchased in discrete units because nonconcavities in utility functions lead the consumer to choose among alternative comer solutions. For example, two television shows aired simultaneously can be consumed in any fractions, but most viewers will prefer to consume all of one and none of the other. Note that many examples could be modelled equally well as cases, (a) or (c).

In addition, even with concave utility functions, particular prices and incomes may lead to corner solutions at which a good is not consumed at all. Empirically, this has led to econometric technigues such as Tobit analysis. Although this is not usually considered discrete choice, we mention it here because the issues inyolyed are formally very similar to those of the other cases.

The problem raised by all these cases for the theoretical derivation of the compensating variation is that discreteness introduces a point of discontimity into the demand functions, and/or a point of non-differentiability into the indirect utility and expenditure functions. Thus, the derivative in equation (2.11) may be undefined at some "crossover" price. The key to the 
result in this section is that it is still possible to integrate over (2.11), since the expenditure function is continuous and has right and left-derivatives at the point in question.

The formal models for the various cases differ in detail, but the proofs for all are essentially similar. We therefore proceed by considering case (a) in a three-good model in which two of the goods are mutually exclusive. The proofs for the other cases and extensions to more than three goods are outlined in Appendix $\mathrm{A}$.

Consider, then,a consumer with utility function

$u=u\left(x_{n}, x_{1}, x_{2}\right)$

where $x_{n}$ is the numeraire good. In order for the possibility of zero consumption of good 1 or 2 to make sense, we assume that utility is finite when either $x_{1}$ or $x_{2}$ is zero. As in the standard case, utility is maximized subject to

$$
x_{n}+p_{1} x_{1}+p_{2} x_{2}=y
$$

$$
x_{j} \geq 0 \quad j=1,2, n
$$

To prevent both $x_{1}$ and $x_{2}$ from being consumed in positive amounts, we impose the constraint

$$
x_{1} x_{2}=0
$$

As in the preyious section, we assume interior solutions rather than deal explicitly with non-negativity constraints; thus the numeraire and either $x_{1}$ or $x_{2}$ are consumed in positive quantities.

Corner solutions can also be dealt with using the framework developed in this section. See Appendix A for a demonstration. 
Theorem 1 .

Suppose a consumer maximizes, subject to constraints (3.2) through (3.4), a twice differentiable, strictly quasi-concave utility function of the form (3.12. Assume $u$ is finite whenever $x_{1}$ or $x_{2}$ is zero, is strictly increasing in $x_{n}$, and is non-decreasing in $x_{1}$ and $x_{2}$. Let $e\left(p_{1}, p_{2}, u\right)$ be the minimum expenditure required to achieve utility $u$, and let $u^{0}=v\left(p_{1}^{0}, p_{2}, y\right)$ be the value of the indirect utility function ${ }^{11}$ at initial prices and income. Then the compensating variation for a change in price $P_{1}$ from $P_{1}^{0}$ to $P_{1}^{f}$ is:

$$
e\left(p_{1}^{f}, p_{2}, u^{o}\right)-e\left(p_{1}^{o}, p_{2}, u^{o}\right)=\int_{p_{1}^{0}}^{p_{1}^{f}} x_{1}^{c}\left(p_{1}, p_{2}, u^{o}\right) d p_{1}
$$

where $x_{1}^{c}(\cdot)$. is the compensated demand function for good 1 defined by

$$
x_{1}^{c}\left(p_{1}, p_{2}, u^{o}\right)=x_{1}\left(p_{1}, p_{2}, e\left(p_{1}, p_{2}, u^{o}\right)\right)
$$

proof. Constraint (3.4) requires that consumption of either good 1 or good 2 be zero. If $x_{2}=0$, the optimal amount of $x_{1}$ is found by maximizing $u\left(x_{n}, x_{1}, 02\right.$ subject to $x_{n}+p_{1} x_{1}=y$. The function $u$ is well-behaved when viewed as a function only of $x_{n}$ and $x_{1}$, so this sub-problem is formalIy identical to the problem of the previous section, and leads to well-defined continuously differentiable indirect utility, expenditure, and compensated demand functions, each conditional on $x_{2}=0$. Denoting these by $\tilde{v}_{1}\left(p_{1}, y\right), \tilde{e}_{1}\left(p_{1}, u\right)$, and $\tilde{x}_{1}^{c}\left(p_{1}, u\right)$, respectively, we know from (2.11) that

$$
\partial \tilde{e}_{1} / \partial p_{1}=\tilde{x}_{1}^{c}
$$

${ }^{11}$ so long as the numeraire is perfectly divisible, the assumption that $u$ is strictly increasing in $x_{n}$ and non-decreasing in $x_{2}$ and $x_{2}$ guarantees that the indirect utility function exists and is strictly increasing in $y$, and therefore can be inverted to find the expenditure function. 
similarly, if $x_{1}=0$, the problem of maximizing $u\left(x_{n}, 0, x_{2}\right)$ yields functions $\tilde{v}_{2}\left(p_{2}, y\right), \tilde{e}_{2}\left(p_{2}, u\right)$ and $\tilde{x}_{2}^{c}\left(p_{2}, u\right)$ with the property that

$$
\partial \tilde{e}_{2} / \partial p_{2}=\tilde{x}_{2}^{c}
$$

For any income $\bar{y}$, the choice between good 1 and good 2 will be made by comparing $\tilde{v}_{1}\left(p_{1}, \bar{y}\right)$ with $\tilde{v}_{2}\left(p_{2}, y\right)$. Let $k\left(p_{1}, p_{2}, \bar{y}\right)$ index the larger of the two, with $k=1$ in case of a tie. Then the utility achieved is

$$
\bar{u}=\tilde{v}_{k}\left(p_{k}, \bar{y}\right) \equiv \max \left\{\tilde{v}_{I}\left(p_{2}, \bar{y}\right), \tilde{v}_{2}\left(p_{2}, \bar{y}\right)\right\}
$$

The quantity $\bar{y}$ is therefore the income required to achieve utility $\bar{u}$, both unconditionally and conditionally on choice $k$ :

$$
\bar{y}=e\left(p_{1}, p_{2}, \bar{u}\right)=\tilde{e}_{k}\left(p_{k}, \bar{u}\right)
$$

Letting $j$ index either good $(j=1,2)$, the fact that $\tilde{v}_{j}\left(p_{j}, \bar{y}\right) \leq \bar{u}$ implies

$$
\tilde{e}_{j}\left(p_{j}, \bar{u}\right) \geq \bar{Y} \quad j=1,2
$$

since $\tilde{v}_{j}$ is strictly increasing in $\bar{y}$, and $\tilde{e}_{j}$ is simply its inverse. But (3.10) and (3.11) together imply that

$$
e\left(p_{1}, p_{2}, \bar{u}\right)=\min _{j} \tilde{e}_{j}\left(p_{j}, \bar{u}\right)
$$

Since each of the functions $\tilde{e}_{j}$ is continuously differentiable in price, so is $e$, except at those prices for which $\tilde{e}_{1}=\tilde{e}_{2} ;$ and at these points, 
e is continuous and right-and left-differentiable. 12 Its price derivatives are therefore bounded and piecewise continuous, and hence integrable. 13 Furthexmore,

$$
\partial e / \partial p_{1}= \begin{cases}\partial \tilde{e}_{1} / \partial p_{1} \equiv \tilde{x}_{1}^{c} & \text { if } k=1 \\ \partial \tilde{e}_{2} / \partial p_{1} \equiv 0 & \text { if } k \neq 1\end{cases}
$$

provided the upper and lower expressions are interpreted as the left- and right-derivatives, respectively, at the point of indifference between the two goods.

${ }_{\text {For given }}^{12} p_{2}$ and $u$, let $y^{*}=e_{2}\left(p_{2}, u\right)$. Let $p_{1}^{*}$ be the single value of $P_{1}$ (if any) at which the consumer switches goods. Thus, $\tilde{e}_{1}\left(p_{1}^{*}, u\right)=\tilde{e}_{2}\left(p_{2}, u\right)=e\left(p_{1}^{*}, p_{2}, u\right)$. For $p_{1}<p_{1}^{*}$, good 1 is chosen and $e^{\prime}=\tilde{e}_{1}$; for $p_{1}>p_{1}^{*}$, good 2 is chosen and $e=\tilde{e}_{2}$. Clearly $e$ is continuous at $\mathrm{p}_{1}^{*}$, since $\tilde{e}_{1}=\tilde{e}_{2}$ there. The left-derivative of $e$ with respect to $p_{1}$, evaluated at $p_{1}^{*}$ is

$$
\begin{aligned}
& \lim \frac{e\left(p_{1}, p_{2}, u\right)-e\left(p_{1}^{*}, p_{2}, u\right)}{p_{1}-p_{1}^{*}} \\
= & \lim \frac{p_{1}^{*}}{\frac{\tilde{e}_{1}\left(p_{1}, u\right)-\tilde{e}_{1}\left(p_{1}^{*}, u\right)}{p_{1}-p_{1}^{*}}} \\
= & p_{1} \uparrow p_{1}^{*} \\
= & \left.\left(\partial \tilde{e}_{1} / \partial p_{1}\right)\right|_{p_{1}^{*}},
\end{aligned}
$$

since $\tilde{e}_{1}$ is differentiable. Similarly, the right-derivative exists and is equal to $\partial \tilde{e}_{2} / \partial p_{1}$.

${ }^{13}$ See any calculus text, e,g, Thomas [1960], p. 214. 
It remains only to identify the right-hand-side of $(3,13)$ as the compensated demand function, $x_{1}^{c}\left(p_{1}, p_{2}, \bar{u}\right)$. When good 1 is chosen (given $\left.\mathrm{p}_{1}, \mathrm{p}_{2}, \overline{\mathrm{u}}\right), \quad \mathrm{x}_{1}^{\mathrm{c}}=\tilde{x}_{1}^{\mathrm{c}}$; when good 2 is chosen, $\mathrm{x}_{1}^{c}=0$. Thus, for an infinitesmal change in $P_{1}$, the compensating variation (3.13) reduces to

$$
\partial e\left(p_{1}, p_{2}, \bar{u}\right) / \partial p_{1}=x_{1}^{c}\left(p_{1}, p_{2}, \bar{u}\right)
$$

Evaluating (3.14) at utility $\mathrm{u}^{0} \equiv \max \left\{\mathrm{v}_{1}\left(\mathrm{p}_{2}^{0}, \mathrm{y}\right), \mathrm{v}_{2}\left(\mathrm{p}_{2}, \mathrm{y}\right)\right\}$ and integrating over $p_{1}$ yields $(3.5)$.

$$
\text { Q.E.D. }
$$

A more heuristic discussion of the theorem may be useful at this point. Suppose an infinitesimal change, $d p_{1}$, occurs in the price of good 1 . If a positive amount $x_{1}$ of good 1 is being consumed, then the welfare loss is $x_{1} d p_{1}$. If good $l$ is not being consmed, i.e, $x_{1}=0$, then the welfare loss is again $x_{1} d p_{1}$, which in this case equals zero. If the consumer is just at the point of indifference between goods 1 and 2 , no welfare loss arises from switching from one good to the other. Therefore, integrating over this point of discontinuity adds nothing to the total for a finite change. In every case, then, the welfare loss from an incremental price change is described by the incremental area to the left of the demand curve. If income is compensated as the price changes, this is equivalent to measuring the area to the left of the compensated demand curve. This intuitive discussion applies equally well to cases (b) and (c), mentioned earlier, 14 and to corner solutions.

14 Mäler [1974, Pp. 131-136] deronstrates an even stronger result for case (b), in which the good in question must be purchased in a given quantity or not at all. He shows that, for a fall in the price of such a good, the compensating yariation is given by the area to the left of its ordinary denand curve. This follows from oor result because income effects are absent, and thus the ordinary and compensated demand curves are Identical. So long as the price remains aboye the "critical price" $\mathrm{P}^{*}$ at which the consumer purchases the dis-. crete good, no compensation is required to keep him at the initial utility level; and below the critical price, the compensation cannot affect the amount of the discrete good purchased. However, $R$. Willig has pointed out to us that Mäler is incorrect in stating that the result also holds when the individual is consuming the good, and the price rises above $p^{*}$. This asymetry occurs because for the price rise, the compensating income alters the ritical price itself, and hence the ordinary demand curve and the relevant compense d demand curve are not identical. 
As in the ordinary goods case, we define an aggregate compensated demand function for good $1, x_{1}^{c}$, as the sum of the individual compensated demand functions. It depends upon the prices and the utilities of all consumers. Similarly, define the aggregate expenditure function $E$ as the sum of the individual expenditure functions at arbitrarily selected utility levels. Then, by adding over consumers, we obtain the result that the sum of the individual compensating variations is given by the area to the left of the aggregate compensated demand curve:

$$
\Delta E=\int_{p_{1}}^{p_{1}^{f}} x_{1}^{c}\left(p_{1}, p_{2},\left\{u^{i}\right\}\right) d p_{1}
$$

where $u^{i}$ is the initial utility level of the ith consumer.

\section{Applying the Theorem}

For purposes of applying Theorem 1, it is important to notice that the demand curve in (3.15) is the unconditional demand for good 1 , and is not conditional on the choice of good 1. Both the discrete choice itself and the quantity demanded conditional on that choice are incorporated in $x_{1}^{c}$. To make this distinction clear, write the compensated demand function in equation (3.5), for individual $i$, as

$$
x_{1}^{c i}\left(p_{1}, p_{2}, u^{i o}\right)=\delta_{1}^{c i}\left(p_{1}, p_{2}, u^{i o}\right) \tilde{x}_{1}^{c i}\left(p_{1}, p_{2}, u^{i o}\right)
$$

where $\delta_{1}^{c i}$ is a compensated discrete choice index, i.e., $\delta_{1}^{c i}$ is 1 if good 1 is chosen and 0 otherwise, assuming that price changes are compensated in order to permit achievement of initial utility level $u^{i 0}$. The compensated demand conditional on choice of good $1, \tilde{x}_{1}^{c i}$, is defined as in the above proof. Adding 
the right-hand sides of equation (3.16) for the $\mathrm{N}$ individuals in the economy yields an alternative version of (3.15):

$$
\Delta E=\int_{P_{1}}^{p_{1}^{f}} \sum_{i=1}^{N} \delta_{1}^{c i}\left(p_{1}, p_{2}, u^{i o}\right) \tilde{x}_{1}^{c i}\left(p_{1}, p_{2}, u^{i o}\right) d p_{1} .
$$

There are two important problens which must be solved in order to make equation (3.17) useful for applied work. First, an investigator cannot know with certainty whether or not a representative individual will consume a given discrete good: All that can be assigned is the probability $\pi_{j}^{i}$ that the good will be purchased, conditional upon a set of measurable characteristics (race, sex, etc.) as well as prices and income. An attractive way to model this is to assume that each individual's utility function is deterministic (as in the preceding section), but that because of factors unobservable to the investigator, the outcome appears random. ${ }^{15}$ Thus as we move to applications of our theorem and attach probabilistic interpretations to variables that were heretofore deterministic, we are not moving to a different framework, but are dealing with a special case of the model developed above. Replacing tne cnolce inuex in (3.17) with this choice probability converts (3.17) to an equation for

15

This seems to have acquired the name "random utility" approach, in contrast to the "constant utility" approach, in which the utility function itself (or equivalently, the choice mechanism) is viewed as having a random component. Operationally, these two formulations are equivalent, i.e. lead to the same kind of estimating equations. Their interpretations are discussed at length by williams [1977]. 
ti: Expected welfare change. 16

The second problem is that $\delta_{1}^{c i}$ is a compensated discrete choice index; therefore, it should be replaced with a compensated choice probability. We provide in the next sub-section an approximation procedure, analogous to that Eor continuous goods, for doing this.

our method is therefore fully operational provided we can find econometric techniques for estimating the required demand curves. A straightforward grocedure would be to estimate the discrete choice and conditional demand Eu:z=ions jointly using maximum likelihood techniques. Alternatively, a cossistent recursive procedure has been developed by Heckman [1977] .

\section{EI:Usky Effect}

A satisfactory approximation procedure for converting econometric estimates into compensated demand relations must take into account the fact that neither the slutsky equation nor the computation of tax revenues is the

16 Note that on 1 y if the choice probabllity is independent of price $p_{1}$ will the correct answer be obtained by calculating areas for conditional demerd curves and multiplying them by the probabilities. Thus, for example, Eeldstein and Friedman [1977] are correct in using the latter procedure to calculate welfare effects of changes in the price of health insurance, secause in their model the probability of illness is assumed to be exogenous. Forever, one must not be misled into thinking their procedure is generalizaile to endogenous probabilities. 
same for discrete as for continuous goods, because the nature of the income effects is fundamentally changed. In the continuous case, it is at least reasonable to suppose that all consumers have identical income slopes for good 1 ; this permits the slutsky equation to be aggregated, and makes plausible the general equilibrium assumption that tax revenues are redistributed so as to return all consumers to their initial utility levels. In the discrete case, however, we explicitly recognize a group whose consumption of good 1 is zero throughout a range of incomes, and thus the analysis must be modified. In order to focus on the issue of discreteness per se, it is useful to abstract from other differences among individuals by assuming $\mathrm{N}$ consumers who differ only in their preferences between goods 1 and $20^{17}$ Thus, they have identical incomes $y$, and identical conditional Marshallian and compensated demand functions $\tilde{x}_{1}\left(p_{1}, y\right)$ and $\tilde{x}_{1}^{c}\left(p_{1}, u\right)$, respectively. This is, of course, a very restrictive case. However, it is useful in that it highlights the important differences that appear when discreteness is explicitly taken into account. If the assumptions of this section seem too restrictive for a given problem, they can be relaxed, elthough the results will be less intuitive and computationally more complicated.

${ }^{17}$ Assume, for example, that utility for the $i$ th individual is given by $u^{i}\left(x_{n}, x_{1}, x_{2}\right)=f\left(x_{n}, x_{1}, x_{2}\right)+\varepsilon_{1}^{i} j_{1}+\varepsilon_{2}^{i} \delta_{2}$, where $\delta_{j}=1$ if $x_{j}$ is chosen and $=0$ otherwise $(j=1,2)$, and where $\varepsilon_{1}^{i}$ and $\varepsilon_{2}^{i}$ are constants. 
The slutsky equation for this model is

$$
\frac{\partial \tilde{x}_{1}^{c}}{\partial p_{1}}=\frac{\partial \tilde{x}_{1}}{\partial p_{1}}+\tilde{x}_{1} \frac{\partial \tilde{x}_{1}}{\partial y}
$$

Now let $\pi_{1}\left(p_{1}, p_{2},\left\{y^{i}\right\}\right)$ be the fraction choosing good 1 at the given prices and incomes. In analogy to the compensated demand function, define the compensated choice probability

$$
\pi_{1}^{c}\left(p_{1}, p_{2},\left\{u^{i}\right\}\right)=\pi_{1}\left(p_{1}, p_{2},\left\{e^{i}\left(p_{1}, p_{2}, u^{i}\right)\right\}\right)
$$

where $u^{i}$ and $e^{i}$ represent the utility level and the expenditure function, respectively, for consumer $i$.

Define the aggregate quantities:

$$
\begin{aligned}
& x_{1}=\sum_{i}^{\sum x_{1}^{i}}=N \pi_{1} \tilde{x}_{1} \\
& x_{1}^{c}=\sum_{i}^{\sum x^{i c}=N \pi_{1}^{c} \tilde{x}_{1}^{c}} \\
& y=\underset{i}{\sum y^{i}=N y} .
\end{aligned}
$$

Note that since all incomes $y^{i}$ are assumed equal, $x_{1}$ and $\pi_{1}$ depend on them only through aggregate income $Y$. Hence we may write;

$$
\begin{aligned}
& \pi_{1}=\pi_{1}\left(P_{1}, P_{2}, Y\right) \\
& X_{1}=X_{1}\left(P_{1}, P_{2}, Y\right)=N \pi_{1}\left(P_{1}, P_{2}, Y\right) \tilde{x}_{1}\left(P_{1}, P_{2}, Y / N\right) .
\end{aligned}
$$

Differentiating (3.19) at an initial point for which $x_{1}^{c}=x_{1}$ and $\pi_{1}^{c}=\pi_{1}$, and applying our previous result (3.14), yields the choiceprobability analogue to the slutsky equation: 


$$
\begin{aligned}
\frac{\partial \pi_{1}^{c}}{\partial p_{1}} & =\frac{\partial \pi_{1}}{\partial p_{1}}+\sum \frac{\partial \pi_{1}}{i} \frac{\partial e^{i}}{\partial p_{1}^{i}} \\
& =\frac{\partial \pi_{1}}{\partial p_{1}}+x_{1} \frac{\partial \pi_{1}}{\partial q}
\end{aligned}
$$

Equations (3.18) through (3.25) taken together yield a slutsky-like equation for the aggregate demand functions;

$$
\left.\frac{\partial x_{1}^{c}}{\partial p_{1}}=\frac{\partial x_{1}}{\partial p_{1}}+\frac{x_{1}}{\pi_{1}} \cdot \frac{\partial x_{1}}{\partial Y}-\left(1-\pi_{1}\right) \frac{x_{1}}{\pi_{1}} \frac{\partial \pi_{1}}{\partial Y}\right] \text {. }
$$

In the special case $\partial \pi_{1} / \partial Y=0$, equation $(3.26)$ is the usual aggregate Slutsky equation, except the income effect is divided by $\pi_{1}$ and is thus larger than in the continuous case. The intuition behind this follows from the conceptual experiment implicit in the compensating variation measure. Were it required to maintain utility after a price rise $d p_{1}$, it would be necessary to provide compensation equal to $x_{1} d p_{1}$ to that fraction $\pi_{1}$ of the population which consumes good 1. But this woula have the. same effect on consumption as raising all incomes equally, by an aggregate amount $\left(x_{1} / \pi_{1}\right) d_{p_{1}}$, since the extra payments to non-consumers would have no impact (so long as $\partial \pi_{1} / \partial Y=0$ ) on aggregate consumption $x_{1}$. Thus, the compensation would cause consumption of good 1 to rise by $\left(\partial x_{1} / \partial Y\right)\left(x_{1} / \pi_{1}\right) d p_{1}$, which gives the first income-effect term in (3.26). The last term arises from the effects of income compensation on the choice probability itself.

\section{Excess Burden}

Following the procedure of Section II, we approximate the demand curves by straight lines with slopes:

$$
\begin{aligned}
& \partial x_{1} / \partial p_{1}=\alpha \\
& \partial x_{1}^{c} / \partial p_{1}=\alpha^{c} \\
& \partial x_{1} / \partial y=\omega .
\end{aligned}
$$


We also let

$$
\partial \pi_{1} / \partial Y=v
$$

As before, the compensating variation is given by equation (2.16); note, however, that this is no longer equivalent to (2.17).

We next proceed to calcilate tax revenues under (a) partial and (b) general equilibrium assumptions, making use of the "slutsky-like" equation (3.26), which can be written:

$$
\alpha^{c}=\alpha+\left(x_{1} / \pi_{1}\right) \omega-\left(1-\pi_{1}\right)\left(x_{1} / \pi_{1}\right)^{2} v
$$

(a) For the partial equilibrium case, tax revenue is simply given by (2.18), and excess burden by (2.22). Substituting (3.27) into (2.22) yields:

$$
\begin{aligned}
x^{\mathrm{P}} & =\frac{1}{2}\left[-\alpha^{c}+2\left(\mathrm{x}_{1} / \pi_{1}\right) \omega-2\left(1-\pi_{1}\right)\left(\mathrm{x}_{1} / \pi_{1}\right)^{2} v\right]\left(\Delta \mathrm{p}_{1}\right)^{2} \\
& =\frac{1}{2}\left[-\alpha+\left(\mathrm{x}_{1} / \pi_{1}\right) \omega-\left(1-\pi_{1}\right)\left(\mathrm{x}_{1} / \pi_{1}\right)^{2} v\right]\left(\Delta \mathrm{p}_{1}\right)^{2}
\end{aligned}
$$

Note that, in the absence of incone effects on the choice probability $(v=0)$, the excess burden (3.29) is larger than would be calculated from (2.23), if discreteness were ignored.

(b) If tax revenues are returned uniformly in lump sum transfers, equation (2.20) remains valid, but is no longer equivalent to (2.21), corresponding to the fact that the compensation no longer returns each consumer, even approximately, to his initial utility level. Under this regime, the fraction $\pi_{1}$ who paid the tax have their real incomes reduced, while the others have them raised. In neither group are individuals moving 
along their compensated demand curves. Subtracting (2.20) from (2.16) and applying ( 3.27 ) gives the excess burden:

$$
\begin{aligned}
x^{G} & =\frac{1}{2}\left[\alpha^{c}-2 \alpha-2 x_{1} \omega\right]\left(\Delta p_{1}\right)^{2} \\
& =\frac{1}{2}\left[-\alpha^{c}+2\left(\frac{1}{\pi_{1}}-1\right) x_{1} \omega-2\left(1-\pi_{1}\right)\left(\frac{x_{1}}{\pi_{1}}\right)^{2} \nu\right]\left(\Delta p_{1}\right)^{2} \\
& =\frac{1}{2}\left[-\alpha+\left(\frac{1}{\pi_{1}}-2\right) x_{1} \omega-\left(1-\pi_{1}\right)\left(\frac{x_{1}}{\pi_{1}}\right)^{2} \nu\right]\left(\Delta p_{1}\right)^{2}
\end{aligned}
$$

Comparing (3.31) with (2.25), we see again that, in the absence of income effects on the choice probability, the excess burden is larger than that computed by ignoring discreteness, though it is still smaller than in the partial-equilibrius case (3.29).

So in general, if the choice probability is independent of income but the conditional demands have positive income elasticities, the usual approximation procedure which ignores discreteness underestimates the compensating variation and the excess burden of a price rise. There are two reinforcing tendencies causing the result. First, the usual slutsky correction results in an overestimate of the magnitude of the compensated price elasticity, and hence an underestimate of the compensating variation. Second, the ameliorating effects of tax-revenue redistribution on misallocation are less, because some of the distributions are "wasted" on non-consumers of the good in question. We suspect that this result is a special case of a more general proposition that standard procedures tend to underestimate excess burden (i.e., the compensating variation less tax revenues) for groups of non-identical consumers. We conclude this section by conpiling, in Table 3.1, the results for computing excess burdens. The formulae have been converted to elasticity form, using the definitions 


$$
\begin{aligned}
& \varepsilon=\frac{p_{1}}{x_{1}} \frac{\partial x_{1}}{\partial p_{1}} \\
& \eta=\frac{Y}{x_{1}} \frac{\partial x_{1}}{\partial Y} \\
& \psi=\frac{Y}{\pi} \quad \frac{\partial \pi}{\partial Y} \\
& \theta=\frac{x_{1} p_{1}}{Y} \\
& \pi=\pi_{1} .
\end{aligned}
$$

The expressions given are those which should replace $\left[-\varepsilon^{c}\right]$ in the Harberger formula,

$$
x^{G}=\frac{1}{2} x_{1} p_{1}\left[-\varepsilon^{c}\right]\left(\Delta p_{1} / p_{1}\right)^{2}
$$

derived from $(2.24)$.

\begin{tabular}{|c|c|c|}
\hline \multicolumn{2}{|c|}{ TABLE 3.1} \\
\hline \multicolumn{2}{|c|}{ Factors for Computing Excess Eurdens } \\
\hline & Continuous & Discrete \\
\hline Partial equilibrium & $-\varepsilon+\theta \eta$ & $-\varepsilon+\frac{1}{\pi} \theta \eta-\left(\frac{1}{\pi}-1\right) \theta \psi$ \\
General equilibrium & $-\varepsilon-\theta \eta$ & $-\varepsilon+\left(\frac{1}{\pi}-2\right) \theta \eta-\left(\frac{1}{\pi}-1\right) \theta \psi$ \\
\hline
\end{tabular}

Observe that when $\pi=1$, the expressions in the second column equal their counterparts in the first. In both relative and absolute terms, the error introduced by ignoring discreteness is small when practically everybody consumes the good. When $\pi$ tends toward zero, on the other hand, tems involving $\theta$ also tend toward zero, whereas those involving $\theta / \pi$ tend to $\tilde{x}_{1} p_{1} / y^{18}$. Thus, the error induced by ignoring discreteness, 
i.e., the difference between terms in Table 3.1 multiplied by $\frac{1}{2} x_{1} p_{1}\left(\Delta p_{1} / p_{1}\right)^{2}$, tends to zero absolutely (though not as a proportion of excess burden) as $\pi$ approaches zero.

A final issue concerns the conceptual experiment which lies behind the results listed in the table. It is implicitly assumed that tax revenues are returned to the population at large. To the extent that it is possible to target the revenues only to the consumers of the taxed discrete good, the usual formulae would apply without modification. If some targeting occurs but it is incomplete, the excess burden would be somewhere between the "continuous" and "discrete" calculations.

\section{Quality Changes}

Thus far, our focus has been the measurement of price-induced welfare changes. However, in many discrete choice problems the evaluation of quality changes is of primary interest. For example, we may wish to evaluate changes in frequency of bus services in contexts where consumers have a choice between bus and auto; or changes in noise levels when individuals have the options of staying in the affected locale or of moying.

One possibility for dealing with a quality change is to conyert it to an equivalent price change, and then to apply the technique discussed in section III. Unfortunately, this is possible only in the very special case in which all consumers have constant and identical marginal rates of substitution between the releyant quality variable and the numeraire. For example, this assuption is often made in transportation studies. by assuming a single constant value of time for everyone. Demand for a particular transportation service can then be 
viewed as a function of money plus time price, and consumer surplus techniques are applicable. However, this example illustrates the tenuousness of such an assumption, since both theoretical and empirical considerations suggest that value of time depends upon a variety of factors such as the wage rate.

An alternative tack is to extend the approach taken in Section III, by adding a quality variable to the model. Suppose that good 1 in the model of the previous section has associated with it a quality variable described by the scalar $q_{1}$, which is considered exogenous by consumers. (The variable $q_{1}$ could also be interpreted as the level of provision of a public good which is complementary to good 1.) Thus:

$$
u=u\left(x_{n}, x_{1}, x_{2}, q_{1}\right)
$$

where, as before, $u$ is assumed to be finite when either $x_{1}=0$ or $x_{2}=0$. We assume further that quality of good 1 does not matter unless good 1 is being consumed:

$$
\partial u\left(x_{n}, 0, x_{2}, q_{1}\right) / \partial q_{1}=0
$$

As in section III, the indirect utility function and the expenditure function are well-defined, continuous, right-and left-differentiable in all arguments, and satisfy

$$
u=v\left(p_{1}, p_{2}, q_{1}, e\left(p_{1}, p_{2}, q_{1}, u\right)\right)
$$

Two alternative formulations of the problem are obtained by implicitly differentiating (4.3) with respect to $q_{1}$ or $p_{1}$, respectively, keeping in mind that the right- and left-derivatives may differ at the crossover points. Taking the quality-derivative of (4.3) yields

$$
\partial e / \partial q_{1}=-(1 / \lambda) \partial v / \partial q_{1}
$$


where $\lambda \equiv \partial v / \partial y \equiv \partial u / \partial x_{n}$ is the marginal utility of income. This intuitive formula simply states that the marginal willingness-to-pay for a quality change is given by the marginal utility of quality, converted to monetary units via the marginal utility of income. For problems in which the indirect utility function is explicitly specified, as in section $v$ below, equation (4.4) is extremely useful, particularly if it is reasonable to approximate $\lambda$ (an empirical quantity, given the normalization implicit in the econometric procedure) by a constant. However, the constancy of $\lambda$ is in no sense necessary for (4.4) to be valid.

Taking the price-derivative of (4.3), on the other hand, and applying Roy's Identity, yields Shephard's lema, which was the starting point for deriving Theoren 1 of section III. Thus, by simply adding $q_{1}$ to the list of arguments of all the functions, Theorem 1 is seen to remain valid in the present context. This fact enables us to evaluate quality changes in terms of changes in consumer's surplus, along the lines explored by Bradford and Hildebrandt [1977] and willig [1978] for continuous goods.

To see this, assume, following Bradford and Hildebrandt, that when the price of good 1 becomes high enough, the consumer does not care about its quality, presumably because none of the good is being consumed. More precisely, we assume that the quality derivative of the expenditure function becomes arbitrarily small as the price of good 1 rises:

$$
\lim _{p_{1}^{f} \rightarrow \infty} \partial e\left(p_{1}^{f}, p_{2}, q_{1}, u^{o}\right) / \partial q_{1}=0
$$

Thus differentiating our previous result, (3.5), with respect to $q_{1}$ and letting $p_{1}^{f}+\infty$ yields the following result:

\section{Theorem 2.}

Let the utility function (4.1) satisfy (4.2) and all the assumptions of 
Theorem 1. Let $e\left(p_{1}, p_{2}, q_{1}, u\right)$, the minimum expenditure required to achieve utility u subject to constraints (3.2) - (3.4), satisfy (4.5). Then

$$
\frac{\partial}{\partial q_{1}} e\left(p_{1}^{0}, p_{2}, q_{1}, u^{o}\right)=-\frac{\partial}{\partial q_{1}} \int_{p_{1}}^{\infty} x_{1}^{c}\left(p_{1}, p_{2}, q_{1}, u^{0}\right) d p_{1},
$$

where the derivatives are to be interpreted as left- and right-derivatives at points of non-differentiability.

Note that $(4.6)$ is the change in the area to the left of the compensated demand curve as it shifts in response to the change in $q_{1}$. This is the result deriyed for the case of continuous goods by Bradford and Hildebrandt [1977], using a slightly different assumption on $\nabla$. Thus, we have demonstrated that the Bradford-Hildebrandt formla remains valid in the discrete goods case.

Equation (4.6) is easily integrated to obtain the compensating variation for a quality change from $q_{1}^{0}$ to $q_{1}^{f}$ :

$$
\left.\Delta E=-\int_{p_{1}}^{\infty}\left[x_{1}^{c}\left(p_{1}, p_{2}, q_{1}^{f}, u^{0}\right)-x_{1}^{c} p_{1}, p_{2}, q_{1}^{0}, u^{0}\right)\right] d p_{1} \text {. }
$$

Furthemor: direct aggregation of (4.7) is possible to obtain a formula in terms of the aggregate compensated demand function;

$$
\Delta E=-\int_{p_{1}}^{\infty}\left[x_{1}^{c}\left(p_{1}, p_{2}, q_{1}^{f},\left[u^{i}\right\}\right)-x_{1}^{c}\left(p_{1}, p_{2}, q_{1}^{0},\left[u^{i}\right\}\right] d p_{1}\right. \text {. }
$$

\section{v. Application to Econometric Models}

McFadden I1973, 1976] has shown that a broad class of discrete choice models can be deriyed by assuming that each consumer maximizes a utility function with a stochastic term accounting for differences in tastes that are unobseryable to the inyestigator. Since such models underlie the bulk of 
current empirical work on discrete choice, it is useful to examine the form which the results of the previous two sections take when applied to stochastic utility models, in particular to the popular probit and logit models. As noted above, these stochastic utility models can be viewed as special cases of the basic deterministic model discussed in Section III.

In our notation, the assumption behind all these models is that the conditional indirect utility function of consumer $i$ for good $j, \tilde{v}_{j}^{i}$, is additively separable into three components as follows: ${ }^{19}$

$$
\tilde{v}_{j}^{i}\left(p_{j}, z_{j}, y^{i}\right)=v^{i}\left(y^{i}\right)+w_{j}\left(p_{j}, q_{j}, y^{i}, \underline{s}^{i}\right)+\varepsilon_{j}^{i}
$$

where $w_{j}(\cdot)$ is a "universal" or "strict utility" function whose form is identical for all consumers; and where $\varepsilon_{j}^{i}$ is the realization for consumer $i$ of a random variable $\varepsilon_{j}$ which is independent of the arguments of $w_{j}$. The vector $\underline{s}^{i}$ contains observable characteristics of the consumer, and attributes of the discrete goods (e.g., locational attributes) which may vary across consumers.

By assuming a joint probability distribution on $\left\{\varepsilon_{j}\right\}$, we obtain the probability, conditional on prices, quality levels, and observable consumer characteristics, that utility is maximized by choosing good 1:

$$
\pi_{1}^{i}=\operatorname{Prob}\left[\varepsilon_{j}-\varepsilon_{1} \leq w_{1}^{i}-w_{j}^{i}\right. \text { for all j], }
$$

where $w_{j}^{i}$ denotes the second term in (5.1). Given specific forms for the

19. The first term in (5.1) does not enter the econometric specification of the discrete choice model, since it is independent of $j ;$ it has usually been ignored in the literature. The remaining tems have generally been described as the "utility function" though it is clear from the inclusion of price as an argument that they are part of an indirect utility function. A true indirect utility function would have all prices as arguments and would not depend on $j$; hence the qualification "conditional." See small [1977] for a fuller discussion of this point. 
functions $w_{j}$, their parameters (up to a normalization convention) can be estimated from a sample of observed choices by maximizing the likelihood function associated with (5.2).

In order to forecast the aggregate demands, we need to measure the incomes $y^{i}$ and other characteristics $\underline{s}^{i}$ of the individuals in the population under consideration. One way to do this is to sample the population, and assume that each sample member $i$ is representative of a group of $N^{i}$ individuals who are identical with respect to their incomes and measured characteristics. . The probability $\pi_{1}^{i}$ calculated from (5.2) can therefore be interpreted as a prediction of the fraction of this particular class of consumers who will choose good 1; to compute expected aggregate demand from the class, we multiply by the conditional demand function, as in $\left(3^{\circ} .20\right)$ :

$$
\mathrm{x}_{1}^{i}\left(\mathrm{p}_{1}, \mathrm{p}_{2}, \mathrm{q}_{1}, \mathrm{y}^{i}, \underline{s}^{i}\right)=\mathrm{N}^{i} \pi_{1}^{i} \tilde{x}_{1}^{i}
$$

Furthermore, applying Roy's Identity for the conditional demand function $\tilde{x}_{1}^{i}$ in (5.3) yields an expression in terms of the marginal utility of income, $\lambda^{i}:$

$$
x_{1}^{i}\left(p_{1}, p_{2}, q_{1}, y^{i} ; \underline{s}^{i}\right)=-\left(N^{i} / \lambda^{i}\right) \pi_{1}^{i} \partial w_{1}^{i} / \partial p_{1}
$$

In the following discussion, we suppress the superscript $i$ and the explicit dependence on $\underline{s}^{i}$, which is assumed to be fixed.

Having specified functional forms for the components $w_{j}$ of the indirect utility function, and having implicitly normalized by choosing a specific joint probability distribution function for the stochastic term $\varepsilon_{j}$, we are free to make assumptions about $w_{j}$ on the basis of purely empirical considerations. We now make three such assumptions, which are likely to be valid in many applications: (a) that the marginal utility of income, $\lambda$, is approximately independent of the price and quality of good 1; (b) that the discrete goods are sufficiently unimportant to the consumer so that income effects from quality changes are negligible, i.e. that the compensated demand function in (4.6) is adequately approximated by the Marshallian demand function; and (c) that $\partial \mathrm{w}_{1} / \partial q_{1} \rightarrow 0$ as $p_{1} \rightarrow \infty$, a slightly stronger version of (4.5). Equation (4.6) can therefore be aggregated over members 
of this consumer group to yield:

$$
\frac{1}{N} \frac{\partial E}{\partial q_{1}}=\frac{1}{\lambda} \frac{\partial}{\partial q_{1}} \int_{p_{1}}^{\infty} \pi_{1}\left(p_{1}, p_{2}, q_{1}, y\right) \frac{\partial w_{1}\left(p_{1}, q_{1}, y\right)}{\partial p_{1}} d p_{1} .
$$

But (5.2) implies that $\pi_{1}$ depends on its axguments only through the functions $w_{1}$ and $w_{2}$. We may therefore make a change of variable, $w_{1}=w_{1}\left(p_{1}, q_{1}, y\right)$, to write:

$$
\begin{aligned}
& \frac{1}{N} \frac{\partial E}{\partial q_{1}}=\frac{1}{\lambda} \frac{\partial}{\partial q_{1}} \int_{\omega_{1}^{0}}^{\omega_{1}^{\infty}} \pi_{1}\left(\omega_{1}, w_{2}\right) d \omega_{1} \\
& =-(1 / \lambda) \pi_{1}\left(\omega_{1}^{0}, w_{2}\right) \partial \omega_{1}^{0} / \partial q_{1} \text {. }
\end{aligned}
$$

where $w_{1}^{0}=w_{1}\left(p_{1}^{0}, q_{1}, y\right), \quad w_{1}^{\infty}=w_{1}\left(\infty, q_{1}, y\right)$. Use has been made of a standard theorem for differentiating a definite integral with respect to its limits (Thomas [1960], p. 720), plus assumption (c) above. Integrating over

$q_{1}$ from initial to final values, therefore, we have:

$$
(\Delta E) / N=-(1 / \lambda) \int_{w_{1}}^{w_{1}^{f}} \pi_{1}\left(w_{1}, w_{2}\right) d w_{1}
$$

where $w_{1}^{\circ}=w_{1}\left(p_{1}^{0}, q_{1}^{0}, y\right)$ and $w_{1}^{f}=w_{1}\left(p_{1}^{0}, q_{1}^{f}, y\right) \cdot 20$

Equation (5.5) is extremely useful for computing welfare effects using discrete choice models estimated from micro data, since it avoids the explicit use of the aggregate demand functions, which are not normally obtained in closed form from such studies. In fact, though equation (5.5) is derived above using the previous results on aggregate demand curves, it can instead be derived directly from the definition (4.3) of the expenditure function.

${ }^{20}$ Equation (5.5) is easily generalized to many simultaneous price and quality changes, provided the Jacobian matrix $\left(\partial \pi_{i} / \partial w_{j}\right)$ is symetric. In
that case. the following line integral is unique, $i . e$, path-independent (see [Silberberg, 1972]):

$$
(\Delta E) / N=-(1 / \lambda) \int_{W^{0}}^{W_{j}^{ \pm}} \sum_{j}(\underline{w}) d \underline{w}_{j}
$$

where $\underline{w}$ is a vector $\underline{W}$ of components $w_{j}$, and takes initial and final values $\underline{w}^{\circ}$ and $\underline{w}^{f}$ respectively. 
To see this, recall that the previous results were based on shepherd's. lema, obtained by differentiating (4.3) with respect to price. As mentioned in Section IV, one may instead differentiate (4.3) with respect to quality, leading to (4.4). The indirect utility $v$ of $(4.4)$ is equal to $\tilde{v}_{1}$ for that fraction $\pi_{1}$ of the consumer group which chooses good 1 , and is equal to $\tilde{v}_{2}$ for the rest. Since only $\tilde{v}_{1}$ depends on $q_{1}$, aggregating $(4.4)$ and calculating $\partial v_{1} / \partial q_{1}$ from (5.1) yields:

$$
\partial E / \partial q_{1}=N\left(\pi_{1} / \lambda\right) \partial w_{1} / \partial q_{1}
$$

Equation (5.6) is perfectly general, but one must use caution in integrating it, since the income variable which appears as an argument in all the functions is compensated, i.e., is that value which maintains the original utility level. With the assumptions of constant $\lambda$ and negligible income effects, however, integrating (5.6) yields (5.5) directly.

A final point to notice about equation (5.5) is that it applies equally well to a price change, if $w_{1}^{0}$ and $w_{1}^{f}$ are defined as the values taken by $w_{1}$ at the initial and final prices, respectively. This may be seen simply by replacing $q_{1}$ by $p_{1}$ in the above paragraph. Alternatively, the price-change version of (5.5) can be derived directly by integrating (5.4).

In the course of the econometric estimation of the choice model, specific functional forms for the $w_{j}{ }^{\prime s}$ are assumed, and estimates of the coefficients are obtained. Hence, one can compute $w_{1}$ at the initial and final quality levels, and can therefore compute the integral in (5.5). Furthermore, if price is included as a variable in the specification, one has an estimate of $\partial \mathrm{w}_{1} / \partial \mathrm{p}_{1}$ - Using this information along with the conditional demand $\tilde{x}_{1} r$ which is often known, $\lambda$ can be computed by using Roy's Identity. ${ }^{21}$ Equation (5.5)

\footnotetext{
2I More specifically, suppose that $\alpha_{p}$ is the coefficient of the price variable in a probit or logit regression? Then $\lambda=-\alpha_{p} / \tilde{x}_{1}$, which, as noted above, is an empirical quantity given the normalization implicit in econometric procedure.
} 
therefore represents an operational procedure for calculating welfare effects. We illustrate its use below for the binary probit and logit models.

$\underline{\text { Probit }}$

In the binary probit model it is assumed that $\left(\varepsilon_{1}-\varepsilon_{2}\right)$ is a standard normal variate. The probabilities are therefore given by

$$
\begin{aligned}
& \pi_{1}=\Phi\left(w_{1}-w_{2}\right) \\
& \pi_{2}=1-\pi_{1}
\end{aligned}
$$

where $\Phi$ is the cumulative normal distribution function. Formula (5.5) for the compensating yariation becomes;

$$
\begin{aligned}
(\Delta E) / N & =-(1 / \lambda) \int_{w_{1}^{0}}^{w_{1}^{f}} \Phi\left(w_{1}-w_{2}\right) d w_{1} \\
& =-(1 / \lambda) \int_{\omega}^{\omega^{f}} \Phi(\omega) d \omega
\end{aligned}
$$

where $\omega^{0}=w_{1}^{0}-w_{2}$ and $w^{f}=w_{1}^{f}-w_{2}$. Given a probit estimation of the functions $w_{1}$ and $w_{2}$, this quantity can be computed for any price or quality change. 22

22 The generalization to simultaneous changes in two price and two quality variables is straightforward, since the Jacobian condition $\partial \pi_{1} / \partial w_{2}=\partial \pi_{2} / \partial w_{1}$ is satisfied. Equation $(5.5 \mathrm{a})$ in footnote 20 thus becomes

$$
\begin{aligned}
& (\Delta E) / N=-\frac{1}{\lambda} \int_{\underline{W}}^{\frac{w^{f}}{0}}\left\{\Phi\left(w_{1}-w_{2}\right) d w_{1}+\left[1-\Phi\left(w_{1}-w_{2}\right)\right] d w_{2}\right\} \\
& =-\frac{1}{\lambda}\left[\Delta w_{2}+\int_{\omega}^{\omega^{f}} \Phi(\omega) d \omega\right]
\end{aligned}
$$

where $\Delta w_{2}=w_{2}^{f}-w_{2}^{o}$.

Recalling that $w_{j}$ is an indirect utility function, the first tero in (5.7a) is the negative of the willingness to pay for a uniform improvement in both goods of magnitude $\Delta W_{2}$, whereas the second term gives the appropriate consumer surplus for any improvement in good 1 relative to good 2 . 
Logit

The logit model arises from the assumption that the stochastic utility components $\varepsilon_{j}$ are independently and identically distributed with the extreme value or double-exponential distribution [MCFadden, 1973, 1976]. This leads to a formula for the probabilities:

$$
\pi_{\ell}=\frac{\exp \left(w_{\ell}\right)}{\sum_{j=1}^{2} \exp \left(w_{j}\right)} \quad \ell=1,2 .
$$

In this case, the integral in (5.5) can be evaluated explicitly, leading to:

$$
(\Delta E) / N=-(1 / \lambda)\left[\ln \sum_{j} \exp \left(w_{j}\right)\right]_{w_{1}^{0}}^{w_{1}^{f}}
$$

where the square brackets indicate the difference in the expression inside when evaluated at the initial and final points. 23

VI. Conclusion

The analysis and estimation of discrete choice modeis is currently enjoying a popularity which is unlikely to abate in future years. Oltimately, both researchers and policy makers will be interested in ascertaining the welfare implications of these models. The purpose of this paper has been to set forth rigorous procedures for doing so. It has been shown how, under quite general conditions as well as for the special cases of probit and logit analysis, the usual techniques for measuring welfare effects must be modified for discrete choice problems. Particular attention has been focused on how the standard corrections for income effects might be altered. The results apply to the study of both price and quality changes.

23 Like the Probit model, the Logit model satisfies the Jacobian symmetry conditions, and calculation of $(5.5 \mathrm{a})$ for many price and quality changes yields equation (5.9) altered only in that the limits for evaluating the term in the square brackets are the values $\underline{w}$ and $\underline{w}^{\prime}$ taken by the vector of all $w_{i}$ at initial and final points. The tern in square brackets has been identified in the transportation literature as the "inclusive price" or "composite cost" of an alternative composed of several sub-alternatives [Ben-Akiva, 1973; Williams, 1977]. 


\section{APPENDIX A}

\section{A.1 Proof of Theorem 1 for different types of discreteness.}

1. The good may be purchased only in discrete units which are so large that most consumers choose only one or two units.

The utility function is $u\left(x_{n}, x_{1}\right)$ where $x_{n}>0$, and $x_{1}$ can take on values of only unity or zero. Utility is maximized subject to the budget constraint $x_{n}+x_{1} p_{1}=y$. If $x_{1}=0$, the optimal amount of $x_{n}$ is trivially equal to $y$. This sub-problem yields the expenditure function conditional on $x_{1}=0, \tilde{e}_{n}(u)$. Similarly, if $x_{1}=1$, the conditional expenditure function $\tilde{e}_{1}\left(p_{1}, u\right)$ is found trivially. As in the case analyzed in the text, the point of maximum utility is associated with the rinimum of these two expenditure functions:

$$
e\left(p_{1}, \bar{u}\right)=\min \left\{\tilde{e}_{n}(\bar{u}), \tilde{e}_{1}\left(p_{1} \bar{u}\right)\right\}
$$

Since $\tilde{e}_{n}$ and $\tilde{e}_{l}$ are both continuously differentiable in price (with $\partial \tilde{e}_{n} / \partial p_{1} \equiv 02$ so is $e$, except at that price at which $\tilde{e}_{1}=\tilde{e}_{2}$, and at this point $e$ is continuous and right-and left-differentiable. The rest of the argiment follows directly that used in the text.

2. Particular prices and incomes lead to corner solutions at which a good is not consumed at all.

Since we cannot now assume an interior solution, the expenditure function conditional on $x_{1}>0$ may not be well defined. However, it is not difficult to see that continuity and nonsatiability of $u$ guarantees that the expenditure function for the overall problem, $e\left(p_{1}, u\right)$, is continuous everywhere and is differentiable within each of the two regimes $x_{1}=0$ and $x_{1}>0$. Hence is it right- and left-differentiable at every point, and the argument in the text applies. 
3. Goods may be purchased in discrete units because nonconcayities in utility functions lead the consumer to choose among alternative corner solutions.

For cases in which discreteness arises from nonconcavity of the utility function, no general theory is available for use in deriving properties of the resulting demand functions. Indeed, so far as we know, no attempt has yet been made to derive formally statistical discrete choice models for such cases, and to do so would be beyond the scope of this paper. Nevertheless, it is not difficult to see that well-behaved examples can be treated within the framework presented in the text. Suppose, for example, that in a threegood world, all the indifference curves between $x_{1}$ and $x_{2}$ are concave to the origin, but indifference curves between either $x_{1}$ or $x_{2}$ and the numeraire are convex. Then at every price vector, consumption of either $x_{1}$ or $x_{2}$ will be zero; hence the constraint $x_{1} \bar{x}_{2}=0$ can be added without changing the problem. Furthermore, the assumptions guarantee that $u\left(x_{n}, 0, x_{2}\right)$ and $u\left(x_{n}, x_{1}, 0\right)$, viewed as functions of two variables, are well-behaved. Thus the proof of section III applies.

\section{A.2 Proof of Theorem 1 for arbitrary numbers of goods.}

1. More than one continuous good.

The interpretation of $x_{n}$ as a vector of goods presents no problems provided that the discussion of the "standard". case in section II generalizes. That this is true is shown in Varian I1978, pp. 209-211].

2. More than two discrete goods, all mutually exclusive.

Utility is given by $u=u\left(x_{n}, x_{1}, x_{2} \ldots, x_{\ell}\right)$, where $x_{j} \geq 0\left(j=n_{l} l, \ldots l\right)$, and where $x_{k}>0\left(k=1, \ldots\right.$ ll implies that $x_{r}=0$ for $x \neq k$. The budget constraint is $x_{n}+\sum_{k=1} p_{k} x_{k}=y$. If $x_{k}>0$, then utility is found 
by maximizing $u\left(x_{n}, 0, \ldots x_{k}, \ldots, 0\right)$ subject to $x_{n}+p_{k} x_{k}=y$. The function $u$ is well-behaved when viewed as a function only of $x_{n}$ and $x_{k}$, and its maximization leads to a (conditional) continuously differentiable expenditure function $\tilde{e}_{k}\left(P_{k}, u\right)$. The only difference between this case and that discussed in the text is that there are now $\&$ such sub-problems, rather than two. But the idea is the same: utility maximization leads to the expenditure function $e\left(p_{l}, \ldots, p_{\ell}, \bar{u}\right)=\min _{k} \tilde{e}_{k}\left(p_{k}, \bar{u}\right)$. Since each of the $\tilde{e}_{k}$ is continuously differentiable in price,so is $e$ except at those prices at which $\tilde{e}_{\ell}=\tilde{e}_{r}$, and at such cross-over points $e$ is continuous and right- and left-differentiable. The rest of the argument follows directly from the proof of Theorem 1 .

3. More than one set of mutually exclusive discrete goods.

Utility is given by $u\left(x_{n}, x_{11}, x_{12}, x_{21}, x_{22}, \ldots x_{\ell 1}, x_{\ell 2}\right)$, where all the arguments in the utility function are non-negative. The constraints are $x_{k 1} x_{k 2}=0$ for all $k=1, \ell$. The budget constraint is $x_{n}+\sum_{k=1}^{\ell}\left(p_{k 1} x_{k 1}+p_{k 2} x_{k 2}\right)=y$. In this case, we can imagine the individual solving $2^{l}$ sub-problems of the sort discussed in Theorem 1. Each sub-problem arises from maximizing utility with one argument in each of the pairs equal to zero. This leads to well-behaved conditional expenditure functions, tire minimum of which is associated with the consumer's optimum. At each vector of "cross-over" prices, the minimum of these functions is continuous and right- and left-differentiable in each price. The rest of the argument follows as in the text.

\section{APPENDIX B}

In this Appendix we apply the results of Table 3.1 to the problem of estimating the excess burden of the implicit subsidy for owner-occupied housing in the U.S. personal income tax. Our purpose is not to arrive at a definitive 
estimate of the efficiency loss associated with the provision. Such a calculation would necessarily involve re cognition that the relevant income and price elasticities vary across income classes, as does the size of the implicit subsidy itself [Laidler, 1969]. Our goal is merely to take advantage of some "stylized facts" concerning the demand for owner-occupied housing in order to see how the excess burden varies under alternative assumptions.

We begin by discussing briefly the relevant tax provisions. (For a more complete exposition, the reader is referred to Laidler [1969].) Under the U.S. income tax, homeowners are not required to include imputed rent in adjusted gross incame. At the same time, they are allowed to deduct payments for property taxes and mortgage interest. Denote by $d$ the proportion of housing costs that are excluded from the tax base. Then assuming a horizontal supply curve for owner-occupied housing services over the relevant range, the implicit subsidy reduces their price to a fraction (I - Td) of supply price, where $\tau$ is the individual's marginal income tax rate. It is expected that lowering the effective price of owner-occupied housing services increases the demand for housing services by those who would own anyway, and also induces some renters to become homeowners. These aistortions of choice lead to the excess burden which we now seek to estimate.

As the discussion in section III indicates, estimates of the following magnitudes are required to compute the exce:s burden call stated in per household termsl:

1. $\Delta p_{1} / p_{1}$, the percentage deyiation in the price of housing services induced by the implicit subsidy.

We. follow Laidler in taking $d$, the proportion of housing expenditures not subject to tax, as $0.68^{24}$. Putting this together with a marginal tax rate

24 This is based on the following assumptions; rate of return on capital in housing $=6 \%$ of house value, state and local taxes $=1.5 \%$, depreciation $=2.25 \%$, and maintenance costs $=1,25 \%$, 
of 0.25 yields an effective price of housing services of $(1-(.25)(.68))=0.83$. so $\Delta \mathrm{p} / \mathrm{p}=(1-0.83) / 1=0.17$.

2. $x_{1} p_{1}$, expenditures on owner-occupied housing services. Suppose the housing unit is worth $\$ 50,000$, approximately the redian value for the U.S. in 1978. Then given the assumptions in footnote 24 , the expenditure flow is $x_{1} p_{1}=\$ 50,000(0.06+.015+.0225+.0125)=\$ 5500$ per year. In order to convert this figure to per. household terms, it must be multiplied by $\pi$, the value of which is given below.

3. $\Psi$, the elasticity of the probability of owning with respect to income; $\varepsilon$, the ordinary (unconditional) price elasticity of demand for owneroccupied housing; and $\eta$, the (unconditional) income elasticity of demand.

These parameters are computed using results reported in Rosen's [forthcoming] study of the impact upon housing decisions of the personal income tax. The econometric method upon which the results are based is a two-stage technique discussed by Heckman [1977]. In the first stage, a probit. equation for the tenure choice decision is estimated by maximum likeiihood. From the probit equation, it is possible to calculate $\Psi$ by evaluating the probit index at the mean values for price and income, and finding the associated probability of owning. 25 The exercise is then repeated with an income value one percent higher. The implied value of $\Psi$ is 0.485 . Similarly, the price elasticity of the probability of homeownership is found to be -0.469 .

The second stage of the econanetric procedure involves estimating the demand for housing, conditional upon owning. In order to correct for potential selectivity bias in the estinates, a variable baser? upo:a the kills ratio is added to the set of regressors. (See Hecknan [1977] for details.) Using a specification

\footnotetext{
25

The computation assumes that the head of household is a white male
} between 26 and 40 years old, and has one child under the age of 17 . 
which is second order in the logarithms of price and income, it is found that, evaluated at the means, the conditional income and price elasticities are 0.76 and -0.97 , respectively.

Recall, however, that $\varepsilon$ and $\eta$ are unconditional elasticities. It is straightforwari to show that an unconditiosal eiasticity is just the sum of the associated conditional elasticity and probability elasticity. Thus, $\varepsilon=-1.44$ and $\eta=1.25$.

4. $\pi$, the probability of howeownership.

The proportion of homeowners in the U.S. is about 0.64 .

5. $\theta$, the budget share of owner-occupied housing.

As Aaron [1972] shows, the proportion of housing in the budgets of owneroccupiers varies considerably across income groups, but a value of about 0.25 reflects the central tendency reasonably well. To find $\theta$, the overall budget share for owner-occupied housing, we multiply 0.25 by the proportion of homeowners, to find $\theta=0.16[=(.25)(.64)]$.

With these figures in hand, we compute in Table B.l the numerical counterparts to the formulae in Table 3.1. The excess burden lin dollars per household per year) for any set of assumptions is found by multiplying the appropriate number in the table by $\$ 51 \quad\left(=.5 \times 5500 \times 0.64 \times(0.17)^{2}\right)$.

TABLE B.I

\begin{tabular}{|c|c|c|}
\hline & Continuous & Discrete \\
\hline Partial & 1.64 & 1.71 \\
General & 1.24 & 1.31 \\
\hline
\end{tabular}


The table indicates that the "discrete" computations do not differ greatly from their "continuous" analogies. (For the partial equilibrium case the difference is $4.2 \%$, for the general equilibrium case it is $5.7 \%$.) This closeness is due to the fact that both $\pi$, the probability of owning, and $\psi$, the income elasticity of the choice probability, are relatively high for owner-occupied housing. In situations where these parameters are closer to zero, the differences will tend to be more substantial; on the other hand, in situations in which the budget share $\theta$ is lower than that for housing, the differences will tend to be smaller. In this context it should be noted that figures in the "continuous" column already are "corrected" for income effects. This correction (which is often ignored, but which is relatively large in this case due to the size of the budget share) amounts to a $14 \%$ difference in the magnitude of the estimated excess burden. 
Aaron, H., Shelter and Subsidies, Brookings, 1972.

Bailey, N. J., "The Marshallian Demand Curve," Journal of Political Economy (vol. 62, 1954), pp. 255-261.

Ben-Akiva, M., Structure of Travel Demand Models, Ph.D. Dissertation, Massachusetts Institute of Technology (1973).

and S. Lerman, "Disaggregate Travel and Mobility Choice Models and Measures of Accessibility" in Hensher and Stopher (eds.) Proceedings of the Third International Conference on Behavioral Travel Demand Modelling, Croom-HeIm, 1978.

Ben-Porath, Y. and M. Bruno, "The Political Economy of Tax Reform: Israel 1975," Journal of Public Economics (vol. 7, 1977), pp.285-308.

Boskin, M. J., "Taxation, Saving and the Rate of Interest," Journal of Political Economy, (vol. 86, 1978), pp. 53-528.

Bradford, D. and G. Hildebrandt, "Observable Public Good Preferences," Journal of Public Econonics, (vol, 8, 1977), pp. 111-131.

Bruce, N., "A Note on Consumer's Surplus, the Divisia Index, and the Measurement of Welfare Changes," Econometrica, (vol. 45, 1974), pp. 1033-1038.

Chipman, J. S. and J. C. Moore, "Compensating Variation as a Measure of Welfare Change," mimeo, University of Minnesota, 1976a.

$$
\text { , "The Scope of Consumer's Surplus Arguments," }
$$

in A. M. Tang, F. M. Westfield, and J. S. Worley (eds.), Evolution, Welfare, and Time in Economics, D. C. Heath and Company, $1976 \mathrm{~b}$.

Diamond, P. and D. MCFadden, "Some Uses of the Expenditure Function in Public Finance," Journal of Public Econorics, (vol. 3, 1974), pp. 3-22.

Domencich, T. A. and D. MCFadden, Urban Travel Demand: A Behavioral Analysis, North-Holland, 1975.

Feldstein, M. S., "The Welfare Cost of Capital Income Taxation," Journal of Political Econony, (vol. 86, 1978), Pp. 529-552.

and B. Friedman, "Tax Subsidies, the Rational Demand for Insurance and the Health Care Crisis," Journal of Public Economics, (vol. 7, 1377), pp. 155-178.

Friedman, M., "The Marshallian Demand Curve," Journal of Political Economy, (vol. 57, 1949), pp. 463-495.

Harberger, A. C., "Taxation, Resource Allocation and Welfare," in J. Due (ed.), The Role of Direct and Indirect Taxes in the Federal Revenue System, Brookings, 1964 .

Hause, J. C., "The Theory of Welfare Cost Measurement," Journal of Political Economy, (vol. 83, 1975), pp. 1145-1182. 
Heckman, J., "Shadow Prices, Market Wages and Labor Supply," Econometrica (vol. 42, July 1974), PP. 679-694.

, "Sample Selection Bias as a Specification Error," University of Chicago, mimeo, 1977.

Laidlex, D., "Income Tax Incentives for Owner-Occupied Housing," in A. C. Harberger and $M$. J. Bailey (eds.), "The Taxation of Income from Capital, The Brookings Institution, Washington, D. C., 1969.

Ucradden, D., "Conditional Logit Analysis of Qualitative Choice Behavior," in P. Zarembka (ed.), Frontiers of Econometrics, Acaiemic Press, 1973.

, "Quantal Choice Analysis: A Survey, Annals of Economic and Social Measurement (vol. 5, 1976), pp. 363-390.

Säler, K., Environmental Economics, Johns Hopkins, 1974.

Mohring, H., "Alternative Gain and Loss Measures," Western Economic Journal (vol. 9, 1971), pp. 349-368.

Rader, T., "Equivalence of Consumer Surplus, The Divisia Index of Output, and Eisenberg's Addilog Social Utility," Journal of Economic Theory (vol. 13, 1976), Pp. 58-66.

Roinlfs, J., "Evaluation of Changes in a Suboptimal Economy," Review of Economic Studies (vol. XIIII(3), 1976), Pp. 359-362.

Rosen, H. S., "Housing Decisions and the U.S. Income Tax: An Econometric Analysis," Journal of Public Economics (forthcoming).

Seade, Jesus, "Consumer's Surplus and Linearity of Engel's Curves," Economic Journal (vol. 88, September 1978).

Silberberg, E., "Duality and the Many Consumer's Surpluses," American Economic Review (vol. 62, 1972), Pp. 942-952.

Snall, K. A., Bus Priority, Differential Pricir.7, and Investment in Urban Highways, Ph.D. Dissertation, University of California, Berkeley, 1976. "Some Notes on Discrete Choice Models and the Scheduling of Activi-
ties," mimeo, Dept. of Economics, Princeton University, 1977.

Thomas, George B., Calculus and Analytic Geometry, Addison-Wesley, 1960.

Varian, H. R., Microeconomic Analysis, W. W. Norton and Company, 1978.

Williams, H., "On the Formation of Travel Dernand Models and Economic Evaluation Measures of User Benefit," Environment and Planning (vol. 9, 1977), Pp. 285-344.

Willig, R., "Consumer's Surplus Without Apology," American Economic Review (vol. 66, 1976), PP. 589-597.

" "Incremental Consumer's Surplus and Hedonic Price Adjustment," Journal of Econonic Theory (vol. 17, 1978), Pp. 227-253. 